\title{
Strong Synergism of Palmatine and Fluconazole/Itraconazole Against Planktonic and Biofilm Cells of Candida Species and Efflux-Associated Antifungal Mechanism
}

\section{OPEN ACCESS}

Edited by:

Santi M. Mandal,

Indian Institute of Technology

Kharagpur, India

Reviewed by:

Ashok K. Chaturvedi,

The University of Texas at San Antonio, United States

Piyush Baindara,

University of Arkansas for Medical

Sciences, United States

${ }^{*}$ Correspondence:

Jing Shao

ustcnjnusjtu@126.com

Changzhong Wang wangchangzhong53@126.com

tThese authors have contributed equally to this work

Specialty section: This article was submitted to Antimicrobials, Resistance and Chemotherapy,

a section of the journal Frontiers in Microbiology

Received: 10 July 2018 Accepted: 12 November 2018 Published: 03 December 2018

Citation:

Wang T, Shao J, Da W, Li Q Shi G, Wu D and Wang C (2018) Strong Synergism of Palmatine and Fluconazole/Itraconazole Against

Planktonic and Biofilm Cells of Candida Species

and Efflux-Associated Antifungal Mechanism. Front. Microbiol. 9:2892.

doi: 10.3389/fmicb.2018.02892

\section{Tianming Wang ${ }^{1 \dagger}$, Jing Shao ${ }^{2 * t}$, Wenyue $\mathrm{Da}^{2}$, Qianqian $\mathrm{Li}^{2}$, Gaoxiang $\mathrm{Shi}^{2}$, Daqiang Wu ${ }^{2}$ and Changzhong Wang ${ }^{2 *}$}

\begin{abstract}
1 Laboratory of Biochemistry and Molecular Biology, College of Integrated Chinese and Western Medicine (College of Life Science), Anhui University of Chinese Medicine, Hefei, China, ${ }^{2}$ Laboratory of Pathogenic Biology and Immunology, College of Integrated Chinese and Western Medicine (College of Life Science), Anhui University of Chinese Medicine, Hefei, China
\end{abstract}

Fungal infections caused by Candida albicans and non-albicans Candida [NAC] species are becoming a growing threat in immunodeficient population, people with long-term antibiotic treatment and patients enduring kinds of catheter intervention. The resistance to one or more than one conventional antifungal agents contributes greatly to the widespread propagation of Candida infections. The severity of fungal infection requires the discovery of novel antimycotics and the extensive application of combination strategy. In this study, a group of Candida standard and clinical strains including C. albicans as well as several NAC species were employed to evaluate the antifungal potentials of palmatine (PAL) alone and in combination with fluconazole (FLC)/itraconazole (ITR) by microdilution method, checkerboard assay, gram staining, spot assay, and rhodamine $6 \mathrm{G}$ efflux test. Subsequently, the expressions of transporterrelated genes, namely CDR1, CDR2, MDR1, and FLU1 for C. albicans, CDR1 and MDR1 for Candida tropicalis and Candida parapsilosis, $A B C 1$ and $A B C 2$ for Candida krusei, CDR1, CDR2, and SNQ2 for Candida glabrata were analyzed by qRT-PCR. The susceptibility test showed that PAL presented strong synergism with FLC and ITR with fractional inhibitory concentration index $(\mathrm{FICl})$ in a range of 0.0049-0.75 for PAL+FLC and 0.0059-0.3125 for PAL+ITR in planktonic cells, 0.125-0.375 for PAL+FLC and 0.0938-0.3125 for PAL+ITR in biofilms. The susceptibility results were also confirmed by gram staining and spot assay. After combinations, a vast quantity of rhodamine $6 G$ could not be pumped out as considerably intracellular red fluorescence was accumulated. Meanwhile, the expressions of efflux-associated genes were evaluated and presented varying degrees of inhibition. These results indicated that PAL was a decent antifungal synergist to promote the antifungal efficacy of azoles (such as FLC and ITR), and the underlying antifungal mechanism might be linked with the inhibition of efflux pumps and the elevation of intracellular drug content.

\footnotetext{
Keywords: palmatine, fluconazole, itraconazole, Candida species, efflux, resistance
} 


\section{INTRODUCTION}

Candida-related infections are becoming a universal threat to the health of human who usually undergo immunosuppressive therapy or aggressive medical intervention. The most commonly found Candida species is C. albicans, an amicable resident in human intestinal tract and genital mucosal surface which can switch into an opportunistic pathogen when external environmental cues are altered (such as $\mathrm{pH}$, temperature, immunocompetence, etc.) (Poulain, 2013; Sardi et al., 2013). With the expanding spread of antifungal agents and the frequent use of broad-spectrum immune-inhibitors, emerging non-albicans Candida (NAC) species including C. glabrata, C. parapsilosis, C. tropicalis, C. krusei and C. guilliermondii are causing increasingly high morbidity and mortality. Besides C. albicans accounting for most cases of invasive candidosis (ca. 35-55\%) (Messer et al., 2006), the above-mentioned NAC are also capable to cause a series of disturbs ranging from mildly superficial mucosal discomforts to deadly disseminated bloodstream and deep-seated tissue infections. The candidosis incidence attributed to NAC species are reported to be varying in a range of $14-21 \%$ for C. glabrata, $15-23 \%$ C. parapsilosis, $20-45 \%$ for C. tropicalis, $2.7 \%$ for C. krusei, and $0.6-3.7 \%$ for C. guilliermondii depending on infection site and geography (Pfaller et al., 2006, 2014; Savini et al., 2011; Silva et al., 2012; Rodrigues et al., 2014).

The relatively high incidence rates of C. albicans and NAC species are supposed to be closely related with their recalcitrant resistance to conventional antifungal agents including, for example, azoles, polyenes, echinocandins and the unique phenotype biofilms (Silva et al., 2012; Zavrel and White, 2015). Fluconazole (FLC) and itraconazole (ITR) are two commonly prescribed antifungal drugs which exert decent inhibitions on most pathogenic Candida species by interrupting the biosynthesis of the fungal-specific membrane sterol ergosterol. However, C. glabrata, C. krusei, and C. guilliermondii have been revealed to be inherently resistant to azoles (Sanguinetti et al., 2015). Although less primary resistances to FLC are reported in C. albicans (1.4\%), C. parapsilosis (3.6\%) and C. tropicalis (4.1\%), it should be noted that an ascending tendency of acquired resistance to azoles are emerging in the three Candida species which have been recorded to take up $48 \%$ of resistant isolates in a retrospective case-comparator study (Oxman et al., 2010; Pfaller et al., 2010b). Of increasing concern are the frequency of multidrug resistant isolates of C. albicans and NAC which display cross-resistance to azoles in especially high-risk patients receiving antifungal prophylaxis (Pfaller et al., 2010a).

Facing increasing severity of global resistance of Candida species recovered clinically, the lag of effective drugs with antifungal purpose alone and/or in combination with traditional antimycotics is worrying. Palmatine (PAL) is an isoquinoline alkaloid of medicinal plant drug that can be isolated from Rhizoma Coptidis and Mahonia aquifolium. PAL exhibits diverse biochemical and pharmacological functions on jaundice, dysentery, hypertension, inflammation, bacterial, virus and fungal infections with less host toxicity (Vollekova et al., 2003; Ishikawa et al., 2016; Wu et al., 2016). Xiao et al. (2015) reported that PAL in combination with berberine (BER) presented remarkably strong antifungal activities to treat Microsporum canis-induced dermatitis in rabbits. Besides, increasing evidence also favored the anti-Candida effects of PAL, inferring that PAL might deserve for further reversion study of resistance especially to azoles (such as FLC and ITR) and underlying mechanism, for example, related with efflux pumps.

This study aims to study the synergism of PAL with FLC and ITR against $C$. albicans SC5314 and several FLC-resistant clinical isolates as well as five NAC standard isolates including C. glabrata, C. parapsilosis, C. tropicalis, C. krusei, and C. guilliermondii by susceptibility test, spot assay and gram staining. The antifungal effects of PAL alone and in combination with FLC or ITR on rhodamine $6 \mathrm{G}$ efflux and the expressions of efflux pump genes are also examined.

\section{MATERIALS AND METHODS}

\section{Strains and Cultivation}

C. albicans SC5314 was a gift of Prof. Yuanying Jiang, School of Pharmacy, Second Military Medical University (Shanghai, China). Six clinical C. albicans isolates including Z3044, Z2003, Z1402, Z1407, Z826, and Z1309 were donated by Huaiwei $\mathrm{Lu}$, Clinical Laboratory, Anhui Provincial Hospital (Hefei, China). C. parapsilosis ATCC22019 and C. tropicalis GDM2.147 were purchased from Guangdong Culture Collection Center (Guangzhou, China). C. glabrata ATCC2340 and C. krusei ATCC1182 were obtained from Bianzhen Biotech. Co. (Nanjing, China). C. guilliermondii ATCC6260 were acquired from Shfeng Biotech. Co. (Shanghai, China). All of stock cultures of these strains were routinely maintained in Sabouraud's agar and were propagated in Liquid Sabouraud Medium (Hope Biotech Co., Qingdao, China) at $37^{\circ} \mathrm{C}$ for $12-16 \mathrm{~h}$ till the strains reached the exponential growth phase. The revived Candida cells were pooled by centrifugation of $3000 \mathrm{~g}$. After washing twice by sterile phosphate-buffered saline (PBS, Leagene, Beijing, China), the fungal cells were resuspended in RPMI-1640 medium (Invitrogen, Carlsbad, CA, United States) without $\mathrm{pH}$ adjustment and adjusted to a defined cell density using a hemocytometer prior for following tests.

\section{Antifungal Activities of Pal Alone and in Combination With FLC and ITR}

\section{Planktonic Cells}

The initial inoculum was adjusted to $2 \times 10^{3} \mathrm{CFU} / \mathrm{mL}$. The minimum inhibitory concentrations (MICs) of Pal, FLC, and ITR were performed in a 96-well flat-bottomed microplate (Corning, Corning, NA, United States) by microdilution method. The concentrations of the tested drugs were serially twofold diluted in a range of $2-1024 \mu \mathrm{g} / \mathrm{mL}$ for Pal, $0.125-1024 \mu \mathrm{g} / \mathrm{mL}$ for FLC and $0.125-512 \mu \mathrm{g} / \mathrm{mL}$ for ITR, respectively. The fungal cells were incubated with the drugs used at $37^{\circ} \mathrm{C}$ for $48 \mathrm{~h}$. The interaction of two drugs was carried out by checkerboard assay with initial inoculum of $2 \times 10^{6} \mathrm{CFU} / \mathrm{mL}$ at $37^{\circ} \mathrm{C}$ for $48 \mathrm{~h}$ according to Clinical and Laboratory Standards Institute (CLSI) M27-A3 (CLSI, 2008). The concentrations of the tested drugs 
were also serially twofold diluted in a range of $0.125-512 \mu \mathrm{g} / \mathrm{mL}$ for Pal, $0.015625-16 \mu \mathrm{g} / \mathrm{mL}$ for FLC and $0.03125-8 \mu \mathrm{g} / \mathrm{mL}$ for ITR, respectively. The $\mathrm{MIC}_{80}$ was determined as the drug concentration that inhibited $80 \%$ of planktonic fungal cells by comparing the optical density (OD) with that of drug-free control at $630 \mathrm{~nm}$. The fractional inhibitory concentration index (FICI) was calculated as (MIC-PAL in combination/MIC-PAL alone) plus [MIC-FLC (ITR) in combination/MIC-FLC (ITR) alone], in which synergism was interpreted as FICI $\leq 0.5$, indifference was defined as $0.5<$ FICI $<4.0$, and antagonism was FICI $\geq 4.0$ (Odds, 2003).

\section{Biofilm Cell}

The initial fungal cells were set at $2 \times 10^{6} \mathrm{CFU} / \mathrm{mL}$. For sessile MIC (SMIC), the tested concentrations ranged from 1 to $1024 \mu \mathrm{g} / \mathrm{mL}$ for PAL, FLC, and ITR. In checkerboard assay, the final concentrations of the three drugs were modified in a range of $0.03125-512 \mu \mathrm{g} / \mathrm{mL}$. The $\mathrm{SMIC}_{80}$ was defined as the drug concentration that inhibited $80 \%$ of fungal biofilm cells by comparing the metabolic activity with that of drug-free control at $490 \mathrm{~nm}$ using XTT method. The XTT procedures were the same as our previous work (Shao et al., 2015). The sessile fractional inhibitory concentration index (sFICI) was calculated as (SMIC-PAL in combination/SMIC-PAL alone) plus [SMICFLC (ITR) in combination/SMIC-FLC (ITR) alone], in which synergism was interpreted as sFICI $\leq 0.5$, indifference was defined as $0.5<$ sFICI $<4.0$, and antagonism was sFICI $\geq 4.0$ (Shao et al., 2014).

\section{Spot Assay}

The procedures were described as a previous report with less modifications (Mukhopadhyay et al., 2002). Briefly, the revived fungal cells were resuspended and 10-fold diluted by RPMI1640 medium to three final concentrations of $1 \times 10^{2}-1 \times 10^{4}$ $\mathrm{CFU} / \mathrm{mL}$. Five microliters of the prepared serial dilutions of each Candida culture was spotted onto YPD plates in the absence (control) and presence of PAL, FLC, PAL+FLC at the concentrations showing synergism. Growth differences were recorded following incubation of the plates for $48 \mathrm{~h}$ at $37^{\circ} \mathrm{C}$.

\section{Gram Staining}

One hundred microliter strain medium $\left(2 \times 10^{6} \mathrm{CFU} / \mathrm{mL}\right)$ was co-incubated with the same volumes of PAL and/or FLC at the final concentrations showing synergism in susceptibility tests in a 96-well flat-bottomed microplate at $37^{\circ} \mathrm{C}$ for $6 \mathrm{~h}$. The supernatant was then discarded, resuspended with $100 \mu \mathrm{L}$ PBS, stained with Gram solution (Leagene, Beijing, China), observed by oil lens $(\times 1000)$ and photographed by OLYMPUS IX51 (Tokyo, Japan).

\section{Rhodamine 6G Efflux}

The experiment was performed according to the procedures described in one of our previous work with few modifications (Shao et al., 2016). Briefly, two milliliters of fungal culture was firstly adjusted to $2 \times 10^{6} \mathrm{CFU} / \mathrm{mL}$ with RPMI 1640, and then co-incubated with the same volume of PAL, FLC, and PAL+FLC at the concentrations showing synergism at $37^{\circ} \mathrm{C}$ for $24 \mathrm{~h}$. The supernatant was discarded after $2000 \mathrm{~g}$ of centrifugation. The remnants were mixed with $2 \mathrm{~mL}$ sterile PBS for $2 \mathrm{~h}$ of incubation at $37^{\circ} \mathrm{C}$ in an orbital shaker (ca. $200 \mathrm{rpm}$ ). The final concentration of $10 \mu \mathrm{M}$ rhodamine-6G $(150 \mu \mathrm{L})$ was added for $2 \mathrm{~h}$ of incubation at $37^{\circ} \mathrm{C}$ without light. The supernatant was discarded after $3000 \mathrm{~g}$ of centrifugation. The pellets were washed three times by sterile PBS. The glucose required for rhodamine $6 \mathrm{G}$ efflux was dissolved in $\mathrm{PBS}$ to the final concentration of $2 \mathrm{mM}$. The suspension was centrifuged at $3000 \mathrm{~g}$, and $100 \mu \mathrm{L}$ of supernatant was visualized at the excitation wavelength of $525 \mathrm{~nm}$ and the emission wavelength of $550 \mathrm{~nm}$ by an inverted fluorescence microscope IX71 (Olympus, Tokyo, Japan).

\section{Gene Expressions}

The procedures of qRT-PCR analysis were described in one of our previous study with small modifications (Shao et al., 2016). Briefly, $1 \times 10^{6} \mathrm{CFU} / \mathrm{mL}$ of fungal culture was incubated for $24 \mathrm{~h}$ at $37^{\circ} \mathrm{C}$. The fungal cells were then collected by $3000 \mathrm{~g}$ and total RNA samples were extracted according to the instructions of MagExtractor-RNA kit (Toyobo, Tokyo, Japan). Six microliters of extracted total RNA was incubated with $2 \mu \mathrm{L} 4 \times$ DNA Master I (containing gDNA Remover) and $2 \mu \mathrm{L}$ 5RT-Master Mix II, and reverse-transcribed into cDNA as recommended by ReverTra Ace qPCR RT Master Mix with gDNA Remover kit (Toyobo, Tokyo, Japan) with procedures as follows: $65^{\circ} \mathrm{C}$ for $5 \mathrm{~min}$ and $4^{\circ} \mathrm{C}$ for $1 \mathrm{~min}$ for initial RNA denaturation, followed by $37^{\circ} \mathrm{C}$ for $15 \mathrm{~min}, 50^{\circ} \mathrm{C}$ for $5 \mathrm{~min}$, and $4^{\circ} \mathrm{C}$ for $1 \mathrm{~min}$. The prepared cDNA was diluted 10-fold prior to the use for RT-PCR. Primers for C. albicans (Table 1) were designed by Primer Premier 5.0 and synthesized by Sangon Biotech (Shanghai, China), while those for C. tropicalis, C. parapsilosis, C. krusei, and C. glabrata were originated from the studies published previously (Sanguinetti et al., 2005; Ricardo et al., 2014; Souza et al., 2015; Shi et al., 2017). Twenty-five microliters of real time PCR mixture was freshly prepared containing $12.5 \mu \mathrm{L}$ of $2 \times$ SYBR Green Realtime PCR, $1 \mu \mathrm{L}$ of PCR Forward Primer, $1 \mu \mathrm{L}$ of PCR Reverse Primer, $0.5 \mu \mathrm{L}$ of $\mathrm{CDNA}$, and $10 \mu \mathrm{L}$ of ddH2O. The PCR process were performed on ABI7000 fluorescent quantitative PCR system (Applied Biosystem) with following cycles: $95^{\circ} \mathrm{C}$ for $60 \mathrm{~s}$ for pre-denaturation alone with $95^{\circ} \mathrm{C}$ for $15 \mathrm{~s}, 55^{\circ} \mathrm{C}$ for $15 \mathrm{~s}, 72^{\circ} \mathrm{C}$ for $45 \mathrm{~s}$ for a total of 40 cycles. All data were normalized to housekeeping gene ACT1 as the internal reference gene. The relative target-gene expression was calculated as a fold change of $2^{-\Delta \Delta C t}$ value, in which $\Delta \mathrm{Ct}=\mathrm{Ct}^{\text {target gene }}-\mathrm{Ct}^{\text {internal reference genes }}$ as previously described (Livak and Schmittgen, 2001).

\section{Statistical Analysis}

All experiments were performed in triplicate in three individual workdays. The results were recorded as mean \pm standard deviation $(n=3)$ and calculated by SPSS 17.0 (SPSS Inc., Chicago, IL, United States). The data among groups were analyzed by one-way ANOVA with least significance difference (LSD) method, in which $p<0.05$ was considered as statistically significant. 
TABLE 1 | Primers for qRT-PCR.

\begin{tabular}{|c|c|c|}
\hline Genes & Forward $\left(5^{\prime}-3^{\prime}\right)$ & Reverse $\left(5^{\prime}-3^{\prime}\right)$ \\
\hline ACT1 & ACCGAAGCTCCAATGAATCC & CCGGTGGTTCTACCAGAAGAG \\
\hline \multicolumn{3}{|c|}{ C. albicans Z3044/SC5314 } \\
\hline CDR2 & GCCAATGCTGAACCGACAGA & AGGACCAGCCAATACCCCAC \\
\hline MDR1 & CCACTGGTGGTGCAAGTGTT & GGACCACAAACAGCACCCAA \\
\hline CDR1 & TAGCACATCAACTACACGAACGT & AGAGTGAACATTAAGGATGCCATG \\
\hline CDR2 & GTGCTITATGAAGGCTACCAGATT & TCTTAGGACAGAAGTAACCCATCT \\
\hline SNQ2 & ACCATGTGTTCTGAATCAATCAAT & TCGACATCATTACAATACCAGAAA \\
\hline \multicolumn{3}{|c|}{ C. parapsilosis ATCC22019 } \\
\hline CDR1 & ATTTGCCGACATCCACCGTTAGG & ACCATGCTGTTTGCGAGTCCA \\
\hline $\mathrm{ABC} 2$ & CCTITGTTCAGTGCCAGATTG & GTAACCAGGGACACCAGCAA \\
\hline \multicolumn{3}{|c|}{ C. tropicalis GDM 2.147} \\
\hline CDR1 & TGGAAAGAGTTGGAGGGTATGTTA & TCCCAAGGTTTCGCCATC \\
\hline MDR1 & TTGGCGTTAGAGGATTACTाTGG & GAATGAAAACTTCTGGGAAAACTGG \\
\hline
\end{tabular}

\section{RESULTS AND DISCUSSION}

\section{Synergistic Activity of PAL With FLC and ITR Against Planktonic and Biofilm Candida Cells}

In planktonic cells, the susceptibility test showed that the MICs of PAL were in a range of $128-512 \mu \mathrm{g} / \mathrm{mL}$ against $C$. albicans SC5314 and six clinical isolates and $64 \geq 1024 \mu \mathrm{g} / \mathrm{mL}$ against the five NAC isolates. The MICs of PAL ranged from 0.5 to $64 \mu \mathrm{g} / \mathrm{mL}$ in C. albicans isolates and 4 to $128 \mu \mathrm{g} / \mathrm{mL}$ in the five NAC isolates after in combination with FLC compared with the MICs alone (Table 2). Likewise, the MICs of PAL altered between $0.5-16 \mu \mathrm{g} / \mathrm{mL}$ in C. albicans isolates and $2-32 \mu \mathrm{g} / \mathrm{mL}$ in the five NAC isolates following simultaneous use of ITR compared with the MICs alone (Table 3). The FICIs were, respectively, of 0.00490.75 for PAL plus FLC and $0.0059-0.3125$ for PAL plus ITR, reflecting the action mode of PAL+FLC/ITR could be defined as synergism in most isolates tested except C. albicans SC5314 and C. tropicalis GDM 2.147 in PAL plus FLC (Tables 2, 3).

A number of studies evaluated the MICs of PAL against a series of Candida species and found that they were of $\geq 500 \mu \mathrm{g} / \mathrm{mL}$ against C. albicans, C. glabrata, C. tropicalis, C. krusei, and C. guilliermondii, except C. parapsilosis which was inhibited at $15.6 \mu \mathrm{g} / \mathrm{mL}$ (Iwasa et al., 1998; Park et al., 1999; Vollekova et al., 2003). In this study, the MICs of PAL alone were lower than or approximate to $500 \mu \mathrm{g} / \mathrm{mL}$ against most Candida isolates $(11 / 12)$ aside from C. guilliermondii ATCC6260 (MIC > $1024 \mu \mathrm{g} / \mathrm{mL}$ ). This discrepancy might be due to the limited purity of PAL that was extracted from effective part of medicinal plants in those previous studies compared with ours. Intriguingly, the presence of PAL improved tremendously the susceptibility of
Candida species, especially FLC-resistant C. albicans isolates, to FLC by even more than 1000-fold increase. Meantime, we also observed that the addition PAL promoted significantly the efficacy of ITR with an elevation of 2- to 64-fold compared with ITR used alone. These results showed the effectiveness of PAL in combination with FLC and ITR to inhibit planktonic cells of Candida strains.

The biofilm is a self-protected life-mode of Candida species different from the planktonic state with complex structure and powerful resistance to most antimycotics. The formation of biofilm therefore is supposed to be a crucial factor to render the incapability of conventional antifungal agents (Tobudic et al., 2012; Taff et al., 2013). Prior to this study, the antibiofilm potential of PAL and its synergistic effect with azoles has not been documented to our knowledge. Herein, the SMIC 80 were above $1024 \mu \mathrm{g} / \mathrm{mL}$ for PAL, FLC, and ITR being used individually in most tested Candida species, while decreased significantly by 4 - to 128 -fold for PAL and 4- to 32-fold for FLC, respectively, with FICI in a range of $0.125-0.375$ by PAL plus FLC, and reduced remarkably by 8 - to 512 -fold for PAL and 8 - to 256-fold for ITR, respectively, with FICI ranging from 0.0938 to 0.3125 by PAL plus ITR. The pairing of PAL plus FLC showed synergism for all of the tested strains, and so did that of PAL plus ITR except C. glabrata ATCC2340 (Table 3). These results demonstrated that the concomitant uses of PAL and FLC/ITR were applicable in the removal of Candida biofilms.

In the following gram staining test and spot assay, the strong synergisms of PAL plus FLC/ITR were also confirmed. Without drug treatment, as shown, quantities of blastoconidia were observed in the tested strains including C. glabrata ATCC2340, C. parapsilosis ATCC22019, C. guilliermondii ATCC6260, 
TABLE 2 | Interactions of PAL alone/in combination with FLC and PAL alone/in combination with ITR against planktonic cells of Candida spp.

\begin{tabular}{|c|c|c|c|c|c|c|c|}
\hline \multirow{3}{*}{ Strains } & \multirow{2}{*}{\multicolumn{3}{|c|}{$\mathrm{MIC}_{80}$ alone $(\mu \mathrm{g} / \mathrm{mL})$}} & \multirow{2}{*}{\multicolumn{2}{|c|}{$\mathrm{MIC}_{80}$ in combination $(\mu \mathrm{g} / \mathrm{mL})$}} & \multirow{3}{*}{$\begin{array}{c}\text { (Interpretation) } \\
\text { FICI of PAL+FLC }\end{array}$} & \multirow{3}{*}{$\begin{array}{l}\text { (Interpretation) } \\
\text { FICI of PAL+ITR }\end{array}$} \\
\hline & & & & & & & \\
\hline & PAL & FLC & ITR & PAL/FLC & PAL/ITR & & \\
\hline Candida guilliermondii ATCC6260 & $>1024$ & 2 & 128 & $128 / 0.0625$ & $8 / 2$ & 0.1563 (synergism) & 0.0234 (synergism) \\
\hline Candida glabrata ATCC2340 & 512 & 2 & 2 & $128 / 0.0625$ & $32 / 0.125$ & 0.2813 (synergism) & 0.2813 (synergism) \\
\hline Candida tropicalis GDM 2.147 & 64 & 1 & 16 & $4 / 0.5$ & $2 / 2$ & 0.5625 (indifference) & 0.1563 (synergism) \\
\hline Candida krusei ATCC1182 & 512 & 2 & 1 & $128 / 0.125$ & $32 / 0.125$ & 0.3125 (synergism) & 0.1875 (synergism) \\
\hline Candida parapsilosis ATCC22019 & 64 & 2 & 16 & $4 / 0.0625$ & 8/0.5 & 0.0938 (synergism) & 0.1563 (synergism) \\
\hline Candida albicans SC5314 & 128 & 0.5 & 4 & $64 / 0.125$ & $4 / 0.125$ & 0.75 (indifference) & 0.0625 (synergism) \\
\hline Candida albicans Z3044 & 128 & $>1024$ & 4 & $1 / 1$ & $2 / 1$ & 0.0088 (synergism) & 0.2656 (synergism) \\
\hline Candida albicans Z2003 & 128 & $>1024$ & 8 & $1 / 1$ & $16 / 1$ & 0.0088 (synergism) & 0.25 (synergism) \\
\hline Candida albicans Z1402 & 128 & $>1024$ & 4 & $0.5 / 2$ & $2 / 0.5$ & 0.0059 (synergism) & 0.1406 (synergism) \\
\hline Candida albicans Z1407 & 512 & $>1024$ & 4 & $2 / 4$ & $8 / 1$ & 0.0195 (synergism) & 0.2656 (synergism) \\
\hline Candida albicans Z826 & 128 & $>1024$ & 8 & $1 / 1$ & $8 / 2$ & 0.0088 (synergism) & 0.3125 (synergism) \\
\hline Candida albicans Z1309 & 128 & $>1024$ & 8 & $0.5 / 1$ & $8 / 2$ & 0.0049 (synergism) & 0.3125 (synergism) \\
\hline
\end{tabular}

TABLE 3 | Interactions of PAL alone/in combination with FLC and PAL alone/in combination with ITR against biofilm cells of Candida spp.

\begin{tabular}{|c|c|c|c|c|c|c|c|}
\hline \multirow[t]{2}{*}{ Strains } & \multicolumn{3}{|c|}{$\mathrm{SMIC}_{80}$ alone $(\mu \mathrm{g} / \mathrm{mL})$} & \multicolumn{2}{|c|}{ SMIC $_{80}$ in combination $(\mu \mathrm{g} / \mathrm{mL})$} & \multirow[t]{2}{*}{$\begin{array}{c}\text { (Interpretation) } \\
\text { sFICI of PAL+FLC }\end{array}$} & \multirow[t]{2}{*}{$\begin{array}{l}\text { (Interpretation) } \\
\text { sFICI of PAL+ITR }\end{array}$} \\
\hline & PAL & FLC & ITR & PAL/FLC & PAL/ITR & & \\
\hline Candida guilliermondii ATCC6260 & $>1024$ & 8 & 512 & $32 / 256$ & $2 / 64$ & 0.2813 (synergism) & 0.127 (synergism) \\
\hline Candida glabrata ATCC2340 & $>1024$ & $>1024$ & $>1024$ & $256 / 128$ & $512 / 512$ & 0.375 (synergism) & 1 (indifference) \\
\hline Candida tropicalis GDM 2.147 & 256 & $>1024$ & $>1024$ & $8 / 256$ & $16 / 32$ & 0.2813 (synergism) & 0.0938 (synergism) \\
\hline Candida krusei ATCC1182 & $>1024$ & $>1024$ & $>1024$ & $8 / 128$ & $128 / 4$ & 0.1563 (synergism) & 0.1289 (synergism) \\
\hline Candida parapsilosis ATCC22019 & 256 & 2 & 512 & $32 / 0.0625$ & $8 / 128$ & 0.1563 (synergism) & 0.2813 (synergism) \\
\hline Candida albicans SC5314 & $>1024$ & $>1024$ & $>1024$ & $64 / 256$ & $64 / 128$ & 0.3125 (synergism) & 0.1875 (synergism) \\
\hline Candida albicans Z3044 & $>1024$ & $>1024$ & $>1024$ & $64 / 256$ & $16 / 256$ & 0.3125 (synergism) & 0.2656 (synergism) \\
\hline Candida albicans Z2003 & $>1024$ & $>1024$ & $>1024$ & $32 / 256$ & $32 / 128$ & 0.2813 (synergism) & 0.1563 (synergism) \\
\hline Candida albicans Z1402 & $>1024$ & $>1024$ & $>1024$ & $32 / 256$ & $64 / 256$ & 0.2813 (synergism) & 0.3125 (synergism) \\
\hline Candida albicans Z1407 & $>1024$ & $>1024$ & $>1024$ & $64 / 64$ & $32 / 32$ & 0.125 (synergism) & 0.0625 (synergism) \\
\hline Candida albicans Z826 & $>1024$ & $>1024$ & $>1024$ & $64 / 256$ & $64 / 128$ & 0.3125 (synergism) & 0.1875 (synergism) \\
\hline Candida albicans Z1309 & $>1024$ & $>1024$ & $>1024$ & $32 / 128$ & $32 / 64$ & 0.1563 (synergism) & 0.0938 (synergism) \\
\hline
\end{tabular}

C. krusei ATCC1182, and C. tropicalis GDM 2.147. Apart from C. krusei ATCC1182 with very less pseudohyphae, there were absence of hyphal or pseudohyphal forms in the other three isolates. These observations were consistent with the descriptions in several previous literatures, in which it is believed that C. glabrata had entirely no presence of pseudohyphae and hyphae, while the other three strains occasionally displayed pseudohyphae in a strain-dependent manner but were deemed to be unable to generate hyphae (Samaranayake and Samaranayake, 1994; Savini et al., 2011; Silva et al., 2012; Rodrigues et al., 2014). In comparison, C. albicans exhibited abundant hypha with less yeast cells in drug-free control. Following the treatments of PAL and FLC/ITR, the hyphal and blast conidia cells were remarkably reduced (Figures 1A,B). With 10-fold of series dilution, the combination of PAL with FLC/ITR also demonstrated their strong synergistic effects in the spot assay (Figures 2A,B).

\section{Inhibition of PAL in Combination With FLC/ITR on Efflux Pumps}

The rhodamine $6 \mathrm{G}$ is a commonly used fluorescent dye with the same transporters as azoles in yeast (Maesaki et al., 1999). This assay measured the efflux activities in the selected Candida species being incubated with PAL and/or FLC/ITR at the concentrations showing synergism in terms of intracellular fluorescence (red color). As shown, drug-free and single drug induced no or less accumulation of intracellular rhodamine $6 \mathrm{G}$, whereas concomitant use of PAL and FLC resulted in vast appearance of red fluorescence inferring there was a close association of the antifungal effects of PAL and/or FLC/ITR with the normal function of efflux pumps in the Candida species tested (Figures 3A,B).

It is known that two main classes of efflux pumps are considered to mediate the resistance of Candida species, i.e., ABC superfamilies and MFS pumps. The former is driven by ATP 
A

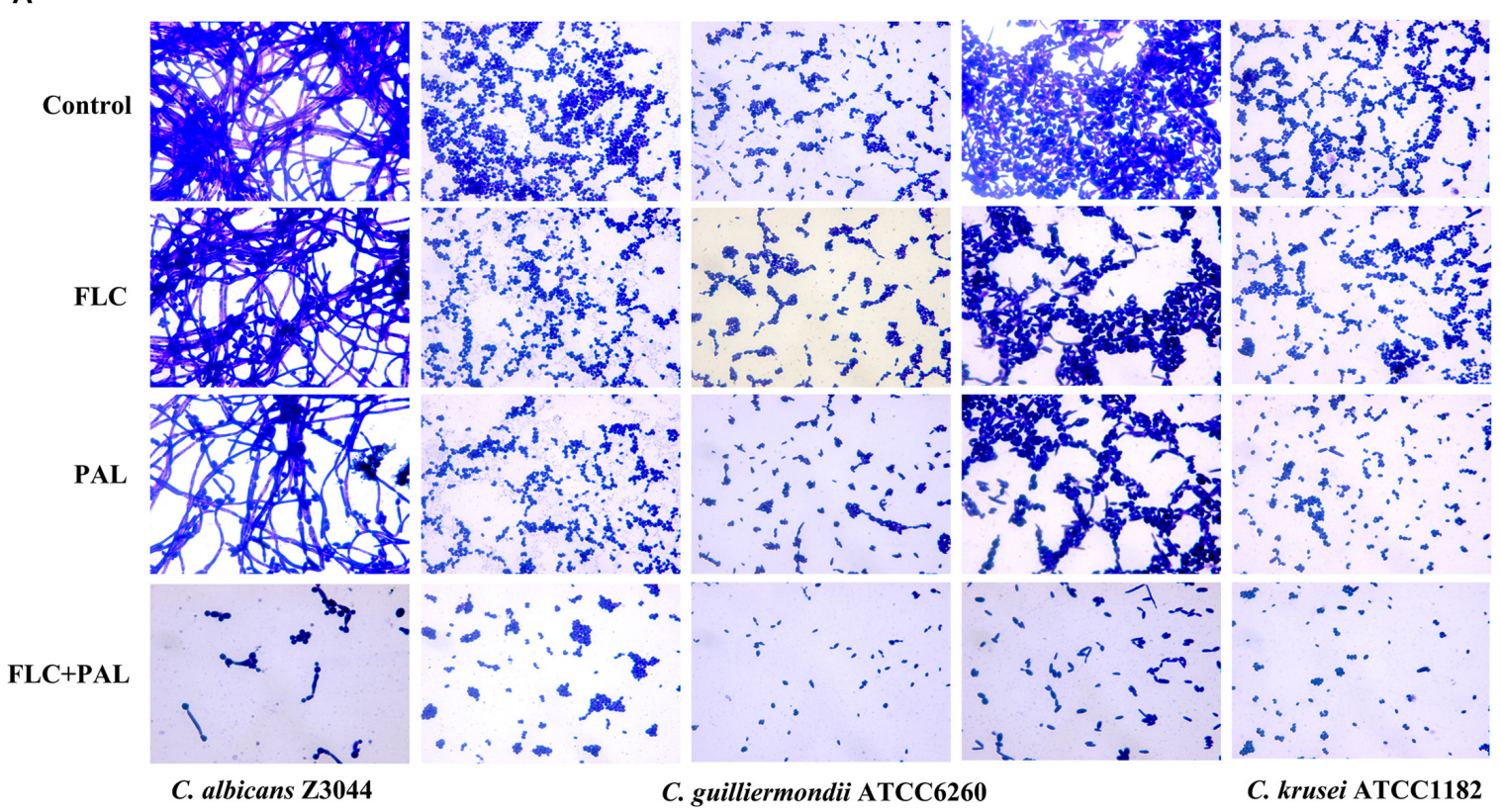

B

C. glabrata ATCC2340

C. parapsilosis ATCC22019

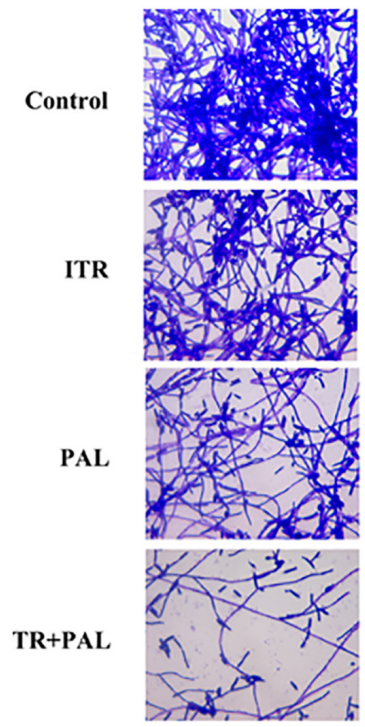

C. albicans SC5314

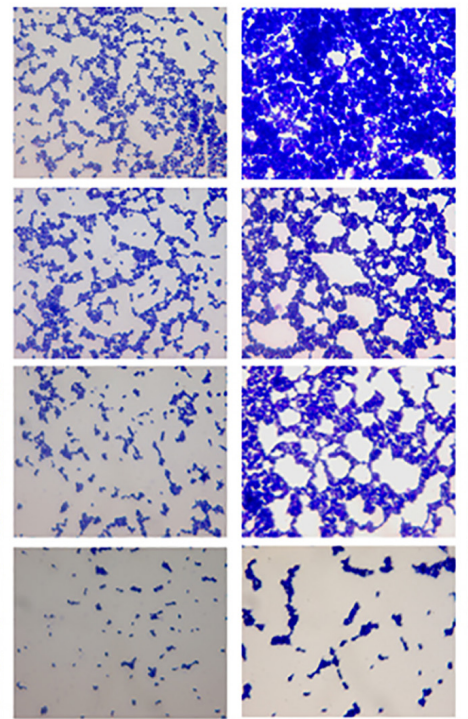

C. guilliermondii ATCC6260

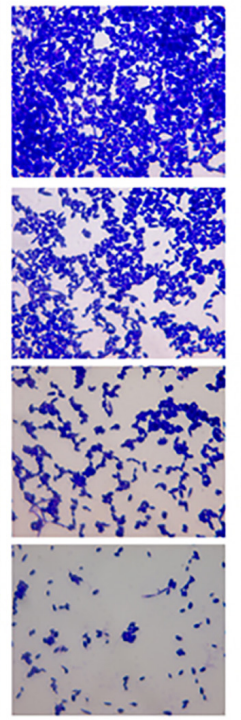

C. parapsilosis ATCC22019

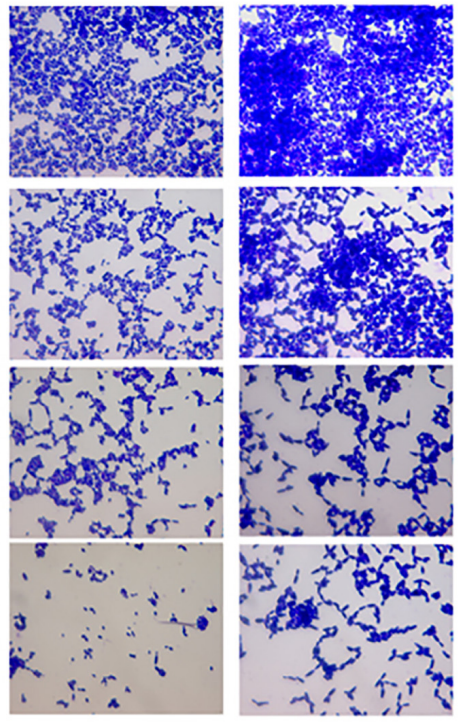

C. krusei ATCC1182

C. glabrata ATCC2340

C. tropicalis GDM 2.14:

FIGURE 1 | Gram staining of Candida species incubated with (A) PAL, FLC, PAL+FLC, and (B) PAL, ITR, PAL+ITR at the concentrations of their MICs showing synergism. The initial inoculum was newly prepared at $2 \times 10^{6} \mathrm{CFU} / \mathrm{mL}$. The drug-free strain-containing medium was set as the control. Oil lens: $\times 1000$.

hydrolysis, and the latter employs the proton-motive force across the membrane (Cannon et al., 2009). Among the Candida species, both transporters are the most extensively studied in C. albicans. Current evidence indicated that CaCDR1, CaCDR2, CaMDR1, and CaFLU1 had specific substrates of conventional antifungal drugs. Overexpressions of $C a C D R 1$ and $C a C D R 2$ are correlative to high-frequency resistance in clinical isolates. $C a C D R 1$ single mutant was hypersensitive to azoles, and CDR1CDR2 double mutant became more susceptible to azoles than $C a C D R 1$ single mutant (Sanglard et al., 1996, 1997). However, accumulating reports demonstrated that $C a C D R 1$ may play a more important role than CaCDR2 in azole resistance (Andes et al., 2006a,b; Holmes et al., 2008). Considering significance of CDR1 and $C D R 2$ versus $M D R 1$ and FLU1 in the resistance of $C$. albicans to azoles, it should be noted that $\mathrm{CaCdr} 1 \mathrm{p}$ and $\mathrm{CaCdr} 2 \mathrm{p}$ possess more azole substrates than CaMdr1p which is relatively specific 


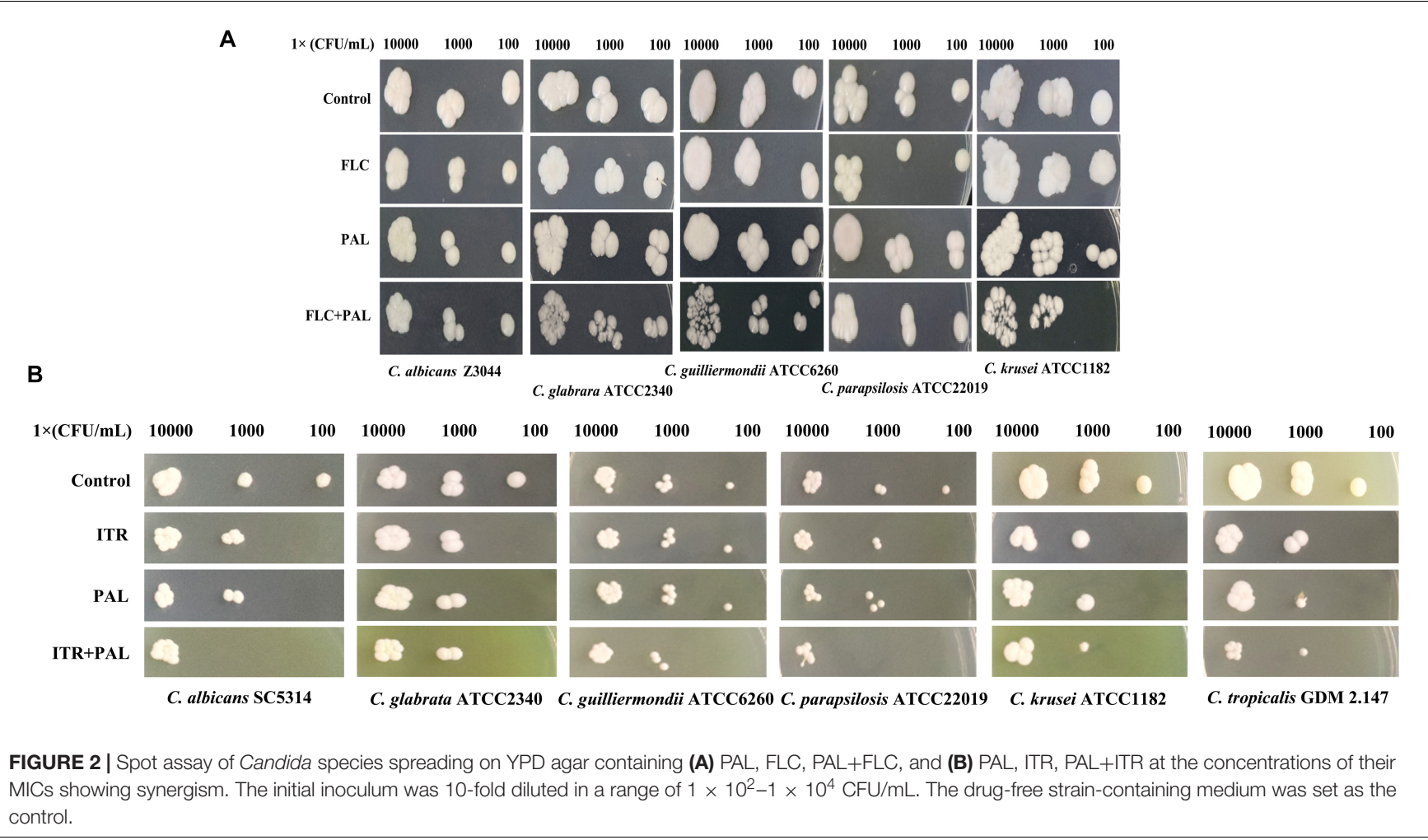

for FLC (Cannon et al., 2009). Of interest, two independent pathways might be possibly present to control the levels of $C D R 1, C D R 2$, and $M D R 1$ in azole-resistant C. albicans as the expressions of $C D R 1$ and $C D R 2$ were upregulated in some FLC-resistant strains, while the expression of MDR1 was upregulated in other strains (Cannon et al., 2009). The expression of FLU1 seemed to be not required in azole resistance of C. albicans as FLU1 mutant affected FLC susceptibility negligibly. Basically, the association of azole resistance with the levels of $\mathrm{ABC}$ superfamilies is comparatively stronger than MFS pumps (Cannon et al., 2009). Our PCR results revealed comparable decreases of $C D R 1$ and $C D R 2$ and considerable reductions of the four genes after treatments of PAL and PAL plus FLC (Figure 4A). We evaluated the expressions of $C D R 1$ and $C D R 2$ belonging to $\mathrm{ABC}$ superfamilies, MDR1 and FLU1 members of MFS pumps in a clinical isolate C. albicans Z3044 exposed to PAL and/or FLC and the standard reference strain C. albicans SC5314 treated with PAL and/or ITR. The results showed that the use of PAL alone with FLC inhibited the expressions of the four genes significantly ( $p<0.05$, Figure $4 \mathbf{A}$ ), while the use of PAL alone with ITR only restrained the expressions of CDR2 and MDR1 $(p<0.01, p<0.05$, Figure $4 \mathbf{B})$. It is speculated that the contributions of $C D R 1, C D R 2, M D R 1$, and FLU1 to azole resistance are dependent on many factors including at least incubation conditions and strain types in C. albicans.

We further evaluated the combined effects of PAL and/or FLC/ITR on the expressions of several efflux-associated genes in C. parapsilosis ATCC22019, C. glabrata ATCC2340, C. krusei
ATCC1182, and C. tropicalis GDM2.147. Our results revealed that (i) PAL plus FLC/ITR caused a great impact on CDR1 and MDR1 $(p<0.05, p<0.01)$ in C. parapsilosis ATCC22019; (ii) PAL plus FLC only affected the expressions of CDR2 $(p<0.01)$, while PAL plus ITR decreased the expressions of $C D R 1$ and $C D R 2$ dramatically $(p<0.01, p<0.01)$ in C. glabrata ATCC2340; (iii) the expressions of $A B C 1$ and $A B C 2$ were lowered $(p<0.01, p<0.05)$ after the use of PAL+ITR, while only $A B C 2$ were suppressed $(p<0.05)$ in the case of PAL+FLC in C. krusei ATCC1182; (iv) the combination of PAL and ITR only influenced MDR1 $(p<0.05)$ in $C$. tropicalis GDM2.147 (Figures 4A,B).

[In NAC species, $\mathrm{ABC}$ superfamilies and MFS pumps are still the most studied efflux pumps in azole resistance, but different from those in C. albicans in types and contributions. The comprehensive knowledge of efflux pumps in NAC species is summarized in several literatures (Cannon et al., 2009; Whaley et al., 2017). In a study of elucidating FLC-resistance mechanism in C. parapsilosis, CDR1 and MDR1 were found to be overexpressed in 16 FLC-resistant isolates and 3 other resistant ones, respectively (Berkow et al., 2015). Several reports also observed the close relationship of $C D R 1$ and MDR1 with FLC-resistance (Grossman et al., 2015; Souza et al., 2015). However, it was also supposed that overexpressions of $C D R 1$ and MDR1 might not be the sole reason responsible for FLCresistance in C. parapsilosis (Berkow et al., 2015). In C. glabrata, there are three $A B C$ transporters identified to be linked directly to azole resistance, namely CDR1, CDR2 (PDH1) and SNQ2 (Sanglard et al., 1999, 2001; Torelli et al., 2008). Whereas MFS 


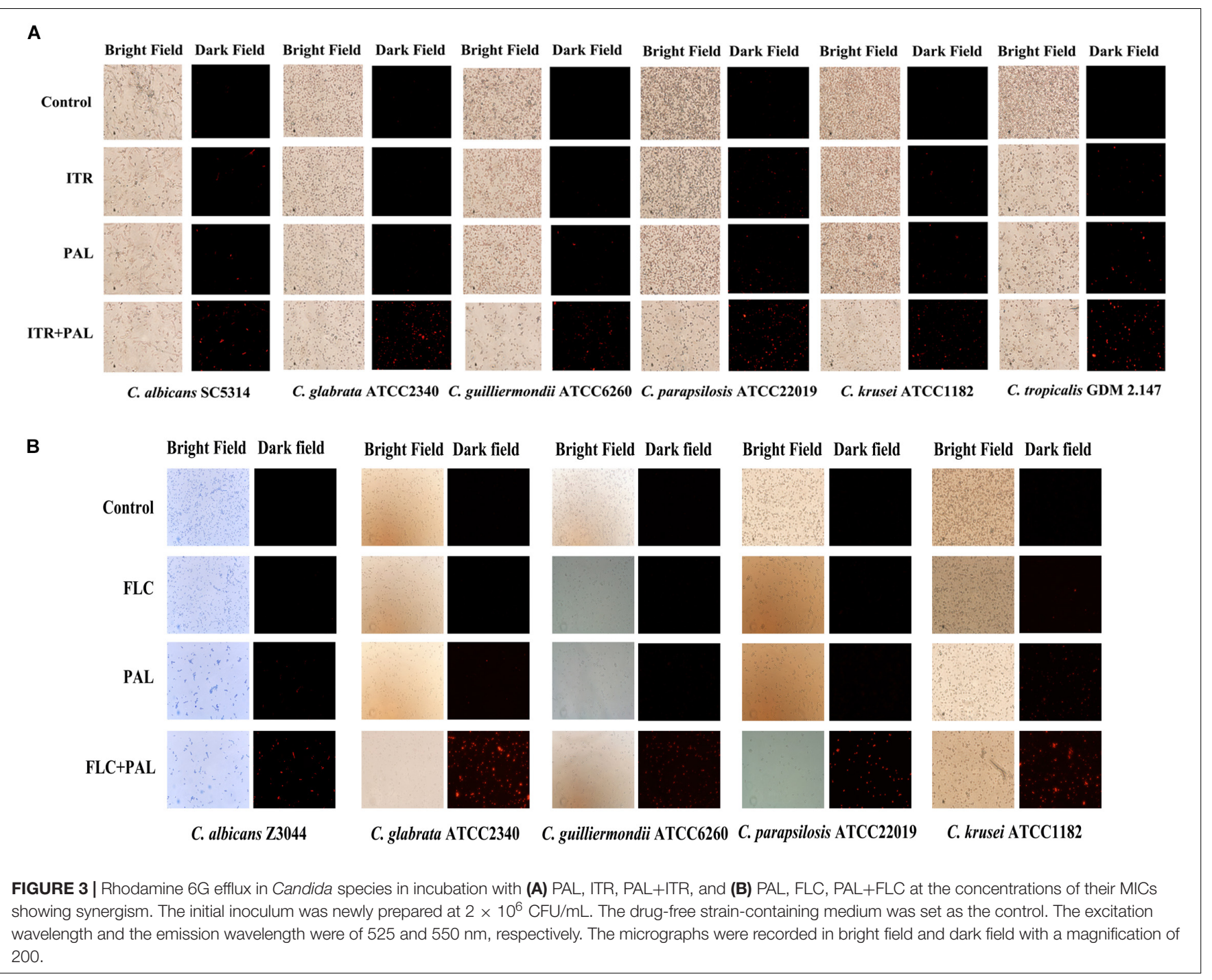

transporters might exert much less impact on azole resistance in C. glabrata (Costa et al., 2016). C. krusei has an inherent instinct of resistance to FLC. This innate resistance mechanism might be connected with ATP-binding cassette transporter Abclp (Katiyar and Edlind, 2001; Lamping et al., 2009). In addition, resistance to ITR was attributed to reduced intracellular drug content and the overexpression of efflux pump Abc2p (Ricardo et al., 2014; He et al., 2015). As with C. tropicalis, the expressions of $C D R 1$ and $M D R 1$ were remarkably upregulated in azole-resistant strains (Barchiesi et al., 2000). We also found a critical role of CDR1 and MDR1 in berberine-treated C. tropicalis isolates (Shi et al., 2017). In our study, accumulated intracellular rhodamine $6 \mathrm{G}$ was an intense sign of the involvement of efflux pumps (Figures 3A,B). Subsequent qRT-PCR analyses confirmed the close relationship of most efflux-associated genes tested with the synergistic antifungal mechanisms of PAL plus FLC/ITR due to their varying degrees of inhibition (Figures 4A,B). Nevertheless, it should be noted that azole resistance is a multifactorial event with more than one gene implicated (such as ERG11), and more studies are necessarily performed to elucidate the involvements of these genes used in azole resistance and crossresistance.

\section{Contributions of Medicinal Plant Drugs and Antifungal Strategy of Combination}

Growing evidence exhibit the huge antifungal potential of quantities of medicinal plant drugs which are easily accessible and less toxic to human with decent antifungal activities and reasonable prices (Li et al., 2013; da Silva et al., 2014; Singh et al., 2015; Sun et al., 2015; Shao et al., 2017). Aside from a few herbal drugs showing relatively low MIC alone (such as berberine and sodium houttuyfonate $\leq 64 \mu \mathrm{g} / \mathrm{mL}$ ), the antiCandida effect is relatively weak in a majority of plant drugs (usually MIC > $256 \mu \mathrm{g} / \mathrm{mL}$ ). The case is also not changed for other non-conventional antifungal agents which are converted to antifungal purpose (Zhou et al., 2012; da Silva et al., 2013; Letscher-Bru et al., 2013; Shahzad et al., 2014). To strengthen the efficacy of individual drug for antifungal usage and traditional antimycotics in the treatment of Candida resistant strains, the 
A

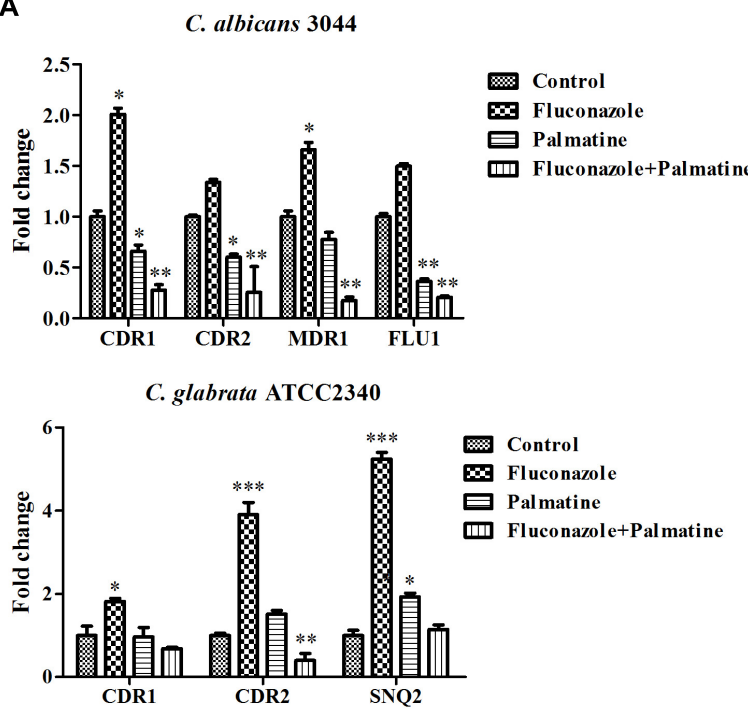

C. parapsilosis ATCC22019
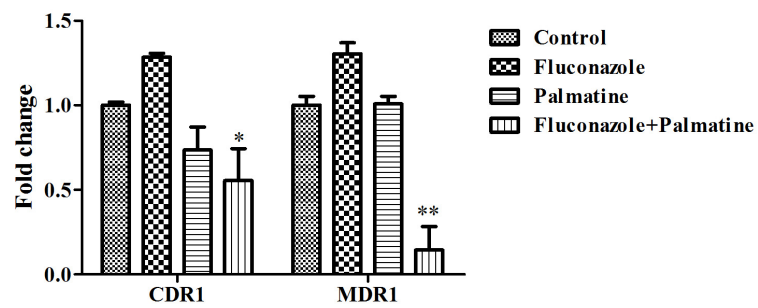

C. krusei ATCC1182

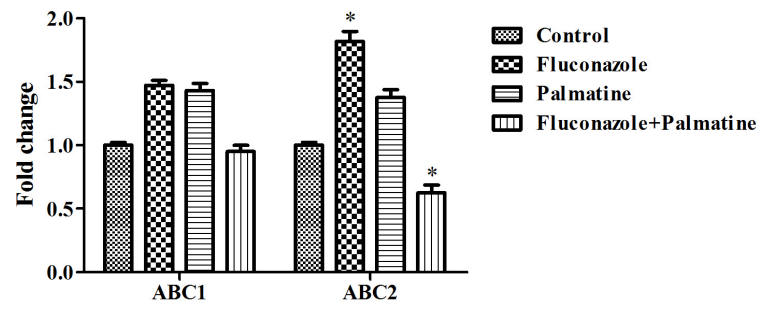

C. parapsilosis ATCC22019

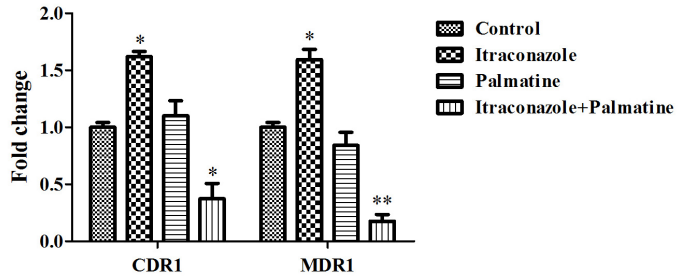

C. krusei ATCC1182
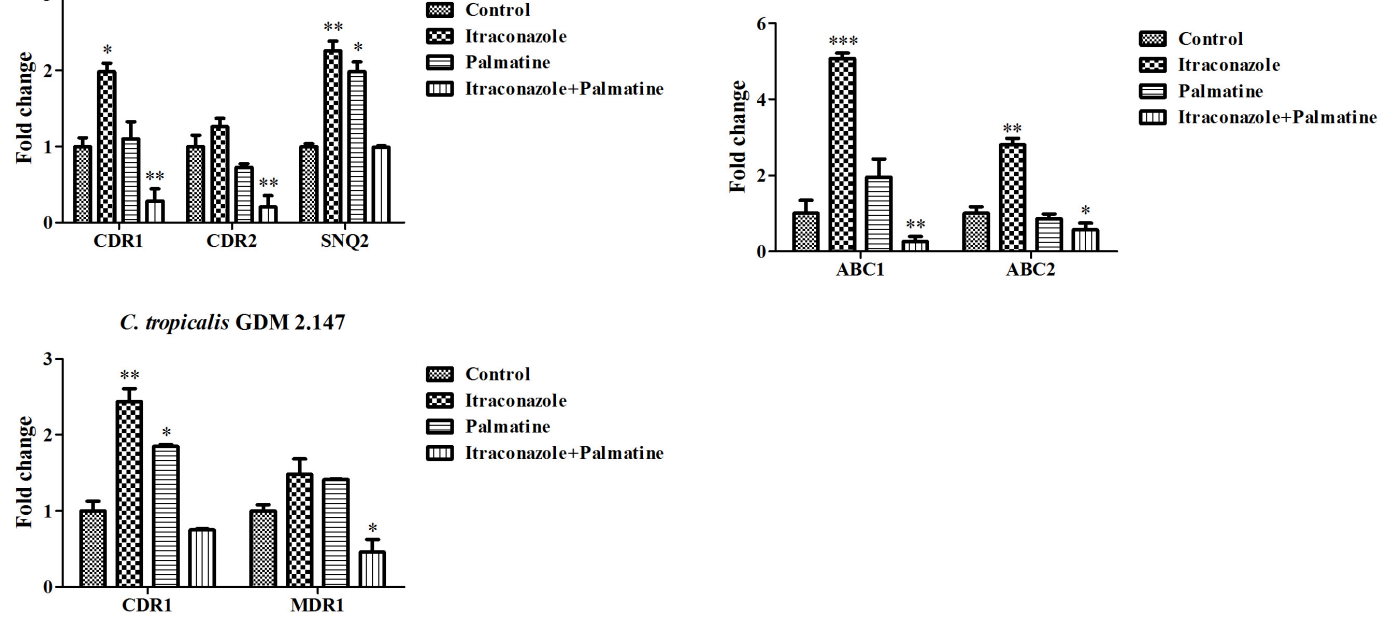

FIGURE 4 | Expressions of efflux-associated genes in Candida species in incubation with (A) PAL, FLC, PAL+FLC, and (B) PAL, ITR, PAL+ITR at the concentrations of their MICs showing synergism. The initial inoculum was newly prepared at $1 \times 10^{6} \mathrm{CFU} / \mathrm{mL}$. The drug-free strain-containing medium was set as the control. ${ }^{*} p<0.05 ;{ }^{* *} p<0.01 ;{ }^{* * *} p<0.001$; compared with the control.

combination strategy is a reliable and feasible approach to inspire the antifungal potentials of the two drugs used which can dramatically lower the MIC of each one. Further, the combination method is also a widely used and effective way in the removal of Candida biofilms. Lu et al. (2017) made a deep and all-sided review on this field. This study is another successful example of drug combination, by which the relative high MICs and SMICs of PAL and FLC alone were dramatically reduced. 


\section{CONCLUSION}

We confirmed the antifungal effects of PAL alone and in combination with FLC/ITR on planktonic and biofilm cells of $C$. albicans as well as NAC species. The gram staining and spot assay results further demonstrated PAL was intensely synergistic with FLC/ITR against most of the tested strains. The rhodamine $6 \mathrm{G}$ and $\mathrm{PCR}$ results inferred that there might be a close association of the antifungal mechanism of PAL plus FLC/ITR with efflux pumps. This study indicated PAL might be a promising synergist against cross-resistance to FLC and ITR in Candida strains.

\section{AUTHOR CONTRIBUTIONS}

TW, WD, QL, and GS performed the experiments. DW reviewed the whole manuscript. JS and CW devised the experiments. JS

\section{REFERENCES}

Andes, D., Forrest, A., Lepak, A., Nett, J., Marchillo, K., and Lincoln, L. (2006a). Impact of antimicrobial dosing regimen on evolution of drug resistance in vivo: fluconazole and Candida albicans. Antimicrob. Agents Chemother. 50, 23742383. doi: 10.1128/AAC.01053-05

Andes, D., Lepak, A., Nett, J., Lincoln, L., and Marchillo, K. (2006b). In vivo fluconazole pharmacodynamics and resistance development in a previously susceptible Candida albicans population examined by microbiologic and transcriptional profiling. Antimicrob. Agents Chemother. 50, 2384-2394.

Barchiesi, F., Calabrese, D., Sanglard, D., Falconi Di Francesco, L., Caselli, F., Giannini, D., et al. (2000). Experimental induction of fluconazole resistance in Candida tropicalis ATCC 750. Antimicrob. Agents Chemother. 44, 1578-1584. doi: 10.1128/AAC.44.6.1578-1584.2000

Berkow, E. L., Manigaba, K., Parker, J. E., Barker, K. S., Kelly, S. L., and Rogers, P. D. (2015). Multidrug transporters and alterations in sterol biosynthesis contribute to azole antifungal resistance in Candida parapsilosis. Antimicrob. Agents Chemother. 59, 5942-5950. doi: 10.1128/AAC.01358-15

Cannon, R. D., Lamping, E., Holmes, A. R., Niimi, K., Baret, P. V., Keniya, M. V., et al. (2009). Efflux-mediated antifungal drug resistance. Clin. Microbiol. Rev. 22, 291-321. doi: 10.1128/CMR.00051-08

CLSI (2008). Reference Method for Broth Dilution Antifungal Susceptibility Testing of Yeasts-Third Edition: Approved Standard M27-A3. Wayne, PA: Clinical and Laboratory Standards Institute.

Costa, C., Ribeiro, J., Miranda, I. M., Silva-Dias, A., Cavalheiro, M., Costa-DeOliveira, S., et al. (2016). Clotrimazole drug resistance in Candida glabrata clinical isolates correlates with increased expression of the drug: $\mathrm{H}(+)$ antiporters CgAqr1, CgTpo1_1, CgTpo3, and CgQdr2. Front. Microbiol. 7:526. doi: $10.3389 /$ fmicb. 2016.00526

da Silva, C. R., De Andrade Neto, J. B., De Sousa Campos, R., Figueiredo, N. S., Sampaio, L. S., Magalhaes, H. I., et al. (2014). Synergistic effect of the flavonoid catechin, quercetin, or epigallocatechin gallate with fluconazole induces apoptosis in Candida tropicalis resistant to fluconazole. Antimicrob. Agents Chemother. 58, 1468-1478. doi: 10.1128/AAC.00 651-13

da Silva, C. R., De Andrade Neto, J. B., Sidrim, J. J., Angelo, M. R., Magalhaes, H. I., Cavalcanti, B. C., et al. (2013). Synergistic effects of amiodarone and fluconazole on Candida tropicalis resistant to fluconazole. Antimicrob. Agents Chemother. 57, 1691-1700. doi: 10.1128/AAC.00966-12

Grossman, N. T., Pham, C. D., Cleveland, A. A., and Lockhart, S. R. (2015). Molecular mechanisms of fluconazole resistance in Candida parapsilosis isolates from a U.S. Surveillance system. Antimicrob. Agents Chemother. 59, 1030-1037. doi: 10.1128/AAC.04613-14 wrote most of the main text. JS, WD, and QL also together arranged the Tables and Figures.

\section{FUNDING}

This work was supported by National Natural Science Foundation of China to JS (81603167) and CW (81573725 and 81774034), Outstanding Young Talents Key Project of Anhui Institution of Higher Education to JS (gxyqZD2018054), Anhui Public Welfare Technology Application Research Project to TW (1604f0804031), Key Project of Natural Science Foundation of Anhui University to TW (KJ2017A287), Discipline Construction Key Program of Anhui University of Chinese Medicine to CW (DC18100042), and Graduate Science and Technology Innovation Fund of Anhui University of Chinese Medicine to WD (2017YB08).

He, X., Zhao, M., Chen, J., Wu, R., Zhang, J., Cui, R., et al. (2015). Overexpression of both ERG11 and ABC2 genes might be responsible for itraconazole resistance in clinical isolates of Candida krusei. PLoS One 10:e0136185. doi: 10.1371/journal. pone. 0136185

Holmes, A. R., Lin, Y. H., Niimi, K., Lamping, E., Keniya, M., Niimi, M., et al. (2008). ABC transporter Cdrlp contributes more than Cdr2p does to fluconazole efflux in fluconazole-resistant Candida albicans clinical isolates. Antimicrob. Agents Chemother. 52, 3851-3862. doi: 10.1128/AAC.00463-08

Ishikawa, S., Tamaki, M., Ogawa, Y., Kaneki, K., Zhang, M., Sunagawa, M., et al. (2016). Inductive effect of palmatine on apoptosis in RAW 264.7 cells. Evid. Based Complement. Alternat. Med. 2016:7262054. doi: 10.1155/2016/7262054

Iwasa, K., Nariba, H., Lee, D.-U., and Kang, S.-I. (1998). Structure-activity relationships of protoberberines having antimicrobial activity. Planta Med. 64, 748-751. doi: 10.1055/s-2006-957572

Katiyar, S. K., and Edlind, T. D. (2001). Identification and expression of multidrug resistance-related $\mathrm{ABC}$ transporter genes in Candida krusei. Med. Mycol. 39, 109-116. doi: 10.1080/mmy.39.1.109.116

Lamping, E., Ranchod, A., Nakamura, K., Tyndall, J. D., Niimi, K., Holmes, A. R., et al. (2009). Abclp is a multidrug efflux transporter that tips the balance in favor of innate azole resistance in Candida krusei. Antimicrob. Agents Chemother. 53, 354-369. doi: 10.1128/AAC.01095-08

Letscher-Bru, V., Obszynski, C., Samsoen, M., Sabou, M., Waller, J., and Candolfi, E. (2013). Antifungal activity of sodium bicarbonate against fungal agents causing superficial infections. Mycopathologia 175, 153-158. doi: 10. 1007/s11046-012-9583-2

Li, D., Xu, Y., Zhang, D., Quan, H., Mylonakis, E., Hu, D., et al. (2013). Fluconazole assists berberine to kill fluconazole-resistant Candida albicans. Antimicrob. Agents Chemother. 57, 6016-6027. doi: 10.1128/AAC.00 499-13

Livak, K. J., and Schmittgen, T. D. (2001). Analysis of relative gene expression data using real-time quantitative PCR and the 2- $\Delta \Delta$ CT method. Methods 25, 402-408. doi: 10.1006/meth.2001.1262

Lu, M., Li, T., Wan, J., Li, X., Yuan, L., and Sun, S. (2017). Antifungal effects of phytocompounds on Candida species alone and in combination with fluconazole. Int. J. Antimicrob. Agents 49, 125-136. doi: 10.1016/j.ijantimicag. 2016.10.021

Maesaki, S., Marichal, P., Bossche, H. V., Sanglard, D., and Kohno, S. (1999). Rhodamine 6G efflux for the detection of CDR1-overexpressing azole-resistant Candida albicans strains. J. Antimicrob. Chemother. 44, 27-31. doi: 10.1093/jac/ 44.1.27

Messer, S. A., Jones, R. N., and Fritsche, T. R. (2006). International surveillance of Candida spp. and Aspergillus spp.: report from the SENTRY Antimicrobial Surveillance Program (2003). J. Clin. Microbiol. 44, 1782-1787. doi: 10.1128/ JCM.44.5.1782-1787.2006 
Mukhopadhyay, K., Kohli, A., and Prasad, R. (2002). Drug susceptibilities of yeast cells are affected by membrane lipid composition. Antimicrob. Agents Chemother. 46, 3695-3705. doi: 10.1128/AAC.46.12.3695-3705.2002

Odds, F. (2003). Synergy, antagonism, and what the chequerboard puts between them. J. Antimicrob. Chemother. 52:1. doi: 10.1093/jac/dkg301

Oxman, D. A., Chow, J. K., Frendl, G., Hadley, S., Hershkovitz, S., Ireland, P., et al. (2010). Candidaemia associated with decreased in vitro fluconazole susceptibility: is Candida speciation predictive of the susceptibility pattern? J. Antimicrob. Chemother. 65, 1460-1465. doi: 10.1093/jac/dkq136

Park, K. S., Kang, K. C., Kim, J. H., Adams, D. J., Johng, T. N., and Paik, Y. K. (1999). Differential inhibitory effects of protoberberines on sterol and chitin biosyntheses in Candida albicans. J. Antimicrob. Chemother. 43, 667-674. doi: $10.1093 / \mathrm{jac} / 43.5 .667$

Pfaller, M. A., Castanheira, M., Messer, S. A., Moet, G. J., and Jones, R. N. (2010a). Variation in Candida spp. Distribution and antifungal resistance rates among bloodstream infection isolates by patient age: report from the SENTRY Antimicrobial Surveillance Program (2008-2009). Diagn. Microbiol. Infect. Dis. 68, 278-283. doi: 10.1016/j.diagmicrobio.2010.06.015

Pfaller, M. A., Diekema, D. J., Gibbs, D. L., Newell, V. A., Ellis, D., Tullio, V., et al. (2010b). Results from the ARTEMIS DISK global antifungal surveillance study, 1997 to 2007: a 10.5-year analysis of susceptibilities of Candida Species to fluconazole and voriconazole as determined by CLSI standardized disk diffusion. J. Clin. Microbiol. 48, 1366-1377. doi: 10.1128/JCM.02117-09

Pfaller, M. A., Diekema, D. J., Mendez, M., Kibbler, C., Erzsebet, P., Chang, S. C., et al. (2006). Candida guilliermondii, an opportunistic fungal pathogen with decreased susceptibility to fluconazole: geographic and temporal trends from the ARTEMIS DISK antifungal surveillance program. J. Clin. Microbiol. 44, 3551-3556. doi: 10.1128/JCM.00865-06

Pfaller, M. A., Jones, R. N., and Castanheira, M. (2014). Regional data analysis of Candida non-albicans strains collected in United States medical sites over a 6-year period, 2006-2011. Mycoses 57, 602-611. doi: 10.1111/myc.12206

Poulain, D. (2013). Candida albicans, plasticity and pathogenesis. Crit. Rev. Microbiol. 41, 208-217. doi: 10.3109/1040841X.2013.813904

Ricardo, E., Miranda, I. M., Faria-Ramos, I., Silva, R. M., Rodrigues, A. G., and Pina-Vaz, C. (2014). In vivo and in vitro acquisition of resistance to voriconazole by Candida krusei. Antimicrob. Agents Chemother. 58, 4604-4611. doi: 10.1128/AAC.02603-14

Rodrigues, C. F., Silva, S., and Henriques, M. (2014). Candida glabrata: a review of its features and resistance. Eur. J. Clin. Microbiol. Infect. Dis. 33, 673-688. doi: 10.1007/s10096-013-2009-3

Samaranayake, Y. H., and Samaranayake, L. P. (1994). Candida krusei: biology, epidemiology, pathogenicity and clinical manifestations of an emerging pathogen. J. Med. Microbiol. 41, 295-310. doi: 10.1099/00222615-41-5-295

Sanglard, D., Ischer, F., and Bille, J. (2001). Role of ATP-binding-cassette transporter genes in high-frequency acquisition of resistance to azole antifungals in Candida glabrata. Antimicrob. Agents Chemother. 45, 1174-1183. doi: 10.1128/AAC.45.4.1174-1183.2001

Sanglard, D., Ischer, F., Calabrese, D., Majcherczyk, P. A., and Bille, J. (1999). The ATP binding cassette transporter gene CgCDR1 from Candida glabrata is involved in the resistance of clinical isolates to azole antifungal agents. Antimicrob. Agents Chemother. 43, 2753-2765. doi: 10.1128/AAC.43.11.2753

Sanglard, D., Ischer, F., Monod, M., and Bille, J. (1996). Susceptibilities of Candida albicans multidrug transporter mutants to various antifungal agents and other metabolic inhibitors. Antimicrob. Agents Chemother. 40, 2300-2305. doi: 10. 1128/AAC.40.10.2300

Sanglard, D., Ischer, F., Monod, M., and Bille, J. (1997). Cloning of Candida albicans genes conferring resistance to azole antifungal agents: characterization of CDR2, a new multidrug ABC transporter gene. Microbiology 143, 405-416. doi: 10.1099/00221287-143-2-405

Sanguinetti, M., Posteraro, B., Fiori, B., Ranno, S., Torelli, R., and Fadda, G. (2005). Mechanisms of azole resistance in clinical isolates of Candida glabrata collected during a hospital survey of antifungal resistance. Antimicrob. Agents Chemother. 49, 668-679. doi: 10.1128/AAC.49.2.668-679.2005

Sanguinetti, M., Posteraro, B., and Lass-Florl, C. (2015). Antifungal drug resistance among Candida species: mechanisms and clinical impact. Mycoses 58, 2-13. doi: $10.1111 /$ myc. 12330

Sardi, J., Scorzoni, L., Bernardi, T., Fusco-Almeida, A., and Giannini, M. M. (2013). Candida species: current epidemiology, pathogenicity, biofilm formation, natural antifungal products and new therapeutic options. J. Med. Microbiol. 62, 10-24. doi: 10.1099/jmm.0.045054-0

Savini, V., Catavitello, C., Onofrillo, D., Masciarelli, G., Astolfi, D., Balbinot, A., et al. (2011). What do we know about Candida guilliermondii? A voyage throughout past and current literature about this emerging yeast. Mycoses 54, 434-441. doi: 10.1111/j.1439-0507.2010.01960.x

Shahzad, M., Sherry, L., Rajendran, R., Edwards, C. A., Combet, E., and Ramage, G. (2014). Utilising polyphenols for the clinical management of Candida albicans biofilms. Int. J. Antimicrob. Agents 44, 269-273. doi: 10.1016/j.ijantimicag.2014. 05.017

Shao, J., Cui, Y., Zhang, M., Wang, T., Wu, D., and Wang, C. (2017). Synergistic in vitro activity of sodium houttuyfonate with fluconazole against clinical Candida albicans strains under planktonic growing conditions. Pharm. Biol. 55, 355-359. doi: 10.1080/13880209.2016.1237977

Shao, J., Lu, K. Q., Tian, G., Cui, Y. Y., Yan, Y. Y., Wang, T. M., et al. (2015). Lab-scale preparations of Candida albicans and dual Candida albicans-Candida glabrata biofilms on the surface of medical-grade polyvinyl chloride (PVC) perfusion tube using a modified gravity-supported free-flow biofilm incubator (GS-FFBI). J. Microbiol. Methods 109, 41-48. doi: 10.1016/j.mimet.2014. 12.006

Shao, J., Wang, T. M., Yan, Y. Y., Shi, G. X., Cheng, H. J., Wu, D. Q., et al. (2014). Matrine reduces yeast-to-hypha transition and resistance of a fluconazoleresistant strain of Candida albicans. J. Appl. Microbiol. 117, 618-626. doi: 10. 1111/jam. 12555

Shao, J., Zhang, M., Wang, T., Li, Y., and Wang, C. (2016). The roles of CDR1, CDR2, and MDR1 in kaempferol-induced suppression with fluconazoleresistant Candida albicans. Pharm. Biol. 54, 984-992. doi: 10.3109/13880209. 2015.1091483

Shi, G., Shao, J., Wang, T., Wu, D., and Wang, C. (2017). Mechanism of berberinemediated fluconazole-susceptibility enhancement in clinical fluconazoleresistant Candida tropicalis isolates. Biomed. Pharmacother. 93, 709-712. doi: 10.1016/j.biopha.2017.06.106

Silva, S., Negri, M., Henriques, M., Oliveira, R., Williams, D. W., and Azeredo, J. (2012). Candida glabrata, Candida parapsilosis and Candida tropicalis: biology, epidemiology, pathogenicity and antifungal resistance. FEMS Microbiol. Rev. 36, 288-305. doi: 10.1111/j.1574-6976.2011.00278.x

Singh, B. N., Upreti, D. K., Singh, B. R., Pandey, G., Verma, S., Roy, S., et al. (2015). Quercetin sensitizes fluconazole-resistant Candida albicans to induce apoptotic cell death by modulating quorum sensing. Antimicrob. Agents Chemother. 59, 2153-2168. doi: 10.1128/AAC.03599- 14

Souza, A. C., Fuchs, B. B., Pinhati, H. M., Siqueira, R. A., Hagen, F., Meis, J. F., et al. (2015). Candida parapsilosis resistance to fluconazole: molecular mechanisms and in vivo impact in infected galleria mellonella larvae. Antimicrob. Agents Chemother. 59, 6581-6587. doi: 10.1128/AAC.01177-15

Sun, L. M., Liao, K., Liang, S., Yu, P. H., and Wang, D. Y. (2015). Synergistic activity of magnolol with azoles and its possible antifungal mechanism against Candida albicans. J. Appl. Microbiol. 118, 826-838. doi: 10.1111/jam.12737

Taff, H. T., Mitchell, K. F., Edward, J. A., and Andes, D. R. (2013). Mechanisms of Candida biofilm drug resistance. Future Microbiol. 8, 1325-1337. doi: 10.2217/ fmb.13.101

Tobudic, S., Kratzer, C., Lassnigg, A., and Presterl, E. (2012). Antifungal susceptibility of Candida albicans in biofilms. Mycoses 55, 199-204. doi: 10. 1111/j.1439-0507.2011.02076.x

Torelli, R., Posteraro, B., Ferrari, S., La Sorda, M., Fadda, G., Sanglard, D., et al. (2008). The ATP-binding cassette transporter-encoding gene CgSNQ2 is contributing to the CgPDR1-dependent azole resistance of Candida glabrata. Mol. Microbiol. 68, 186-201. doi: 10.1111/j.1365-2958.2008.06143.x

Vollekova, A., Kost'alova, D., Kettmann, V., and Toth, J. (2003). Antifungal activity of Mahonia aquifolium extract and its major protoberberine alkaloids. Phytother. Res. 17, 834-837. doi: 10.1002/ptr.1256

Whaley, S. G., Berkow, E. L., Rybak, J. M., Nishimoto, A. T., Barker, K. S., and Rogers, P. D. (2017). Azole antifungal resistance in Candida albicans and emerging Non-albicans Candida species. Front. Microbiol. 7:2173. doi: 10.3389/ fmicb.2016.02173

Wu, J., Xiao, Q., Zhang, N., Xue, C., Leung, A. W., Zhang, H., et al. (2016). Photodynamic action of palmatine hydrochloride on colon adenocarcinoma HT-29 cells. Photodiagnosis Photodyn. Ther. 15, 53-58. doi: 10.1016/j.pdpdt. 2016.05.005 
Xiao, C.-W., Ji, Q.-A., Wei, Q., Liu, Y., and Bao, G.-L. (2015). Antifungal activity of berberine hydrochloride and palmatine hydrochloride against Microsporum canis -induced dermatitis in rabbits and underlying mechanism. BMC Complement. Altern. Med 15:177. doi: 10.1186/s12906-0150680-x

Zavrel, M., and White, T. C. (2015). Medically important fungi respond to azole drugs: an update. Future Microbiol. 10, 1355-1373. doi: 10.2217/FMB.15.47

Zhou, Y., Wang, G., Li, Y., Liu, Y., Song, Y., Zheng, W., et al. (2012). In vitro interactions between aspirin and amphotericin B against planktonic cells and biofilm cells of Candida albicans and C. parapsilosis. Antimicrob. Agents Chemother. 56, 3250-3260. doi: 10.1128/AAC.06082-11
Conflict of Interest Statement: The authors declare that the research was conducted in the absence of any commercial or financial relationships that could be construed as a potential conflict of interest.

Copyright (c) 2018 Wang, Shao, Da, Li, Shi, Wu and Wang. This is an open-access article distributed under the terms of the Creative Commons Attribution License (CC BY). The use, distribution or reproduction in other forums is permitted, provided the original author(s) and the copyright owner(s) are credited and that the original publication in this journal is cited, in accordance with accepted academic practice. No use, distribution or reproduction is permitted which does not comply with these terms. 